\title{
The Commodity Housing Price Analysis Model--Take Haikou (China) as an Example
}

\author{
Bing-Qian Liu ${ }^{1}$, Xiao-Yan Cao ${ }^{1}$, Qi-Fan Yang ${ }^{1} \&$ Yuan-Biao Zhang ${ }^{1,2,3}$ \\ ${ }^{1}$ Mathematical Modeling Innovative Practice Base, Jinan University, Zhuhai Campus, Zhuhai, China \\ ${ }^{2}$ Packaging Engineering Institute, Jinan University, Zhuhai Campus, Zhuhai, China \\ ${ }^{3}$ Key Laboratory of Product Packaging and Logistics of Guangdong Higher Education Institutes, Jinan \\ University, Zhuhai Campus, Zhuhai, China \\ Correspondence: Yuan-Biao Zhang, Packaging Engineering Institute, Jinan University, Zhuhai Campus, Zhuhai \\ 519070, China. E-mail: zybt@jnu.edu.cn
}

Received: May 21, 2018

doi:10.5539/ijef.v10n8p43
Accepted: June 29, 2018

Online Published: June 30, 2018

\begin{abstract}
In recent decade years, the real-estate industry in China has achieved unprecedented development. Correspondingly, the rapid rise in house prices has led the government to introduce a series of macro-control policies. Based on the main regulatory mechanism of the purchase restriction policy, we take Haikou as an example to analysis the probable influence on housing price. We first select indicators from three aspects: supply, demand, and macroeconomic environment, and then establish a gray correlation model to extract the key factors of strong correlation, that is, real- estate investment, CPI, residential housing construction area, residential housing completion area. Moreover, we establish a multiple linear regression model based on GM $(1, \mathrm{n})$ to obtain the multi-function relationship between commercial housing prices and these four key indicators. After that, we establish a population- purchases demand function model to predict the price of commercial housing in the coming year after introducing the purchase restriction policy. More significantly, we conclude that the purchase restriction policy can effectively regulate housing prices in the short term, but the long-term effect is limit.
\end{abstract}

Keywords: multiple grey predicting models, multiple linear regressions, population-purchase demand model

\section{Introduction}

Since the reform of housing market, the rapid development of real-estate industry in China has resulted in the rapid growth of housing prices while improving the housing conditions of residents. Especially since the 21 st century, the housing prices in China have seen spurt growth. To curb the excessive growth of housing prices, the government has launched a series of restriction policies since 2010. The purpose of our paper is to analyze the impact of the restriction purchase policy on the residential housing prices.

For the study of factors influencing commercial housing prices, Malpezzi (1992) used the error correction model to derive the effects of income changes and previous prices on housing prices and short-term supply of weak elasticities. Using quarterly data from 2004 to 2009 and the state-space model, Huang (2010) conducted a dynamic analysis of the impact of land prices and situational income on the price of commercial housing. By establishing VEC model and VAR model, Zhou (2015) analyzed the influence of interest rate changes upon the real-estate market. Yang and He (2016) used family households as a unit to examine the relationship between population migration, urbanization, and the housing market. Combining improved entropy weights and grey correlation analysis, Sun (2017) found that the level of residents' purchasing power and regional economic development level had a significant impact on real estate prices, and followed by the level of infrastructure construction and real estate market environment affected real estate prices. Based on the Kriging spatial interpolation method, Wang et al. (2018) analyzed the trend of house prices in Wuhan, and found that the convenience of transportation, location business districts, ecological environment quality, complete service facilities, and urban planning had a positive and relevant influence on the prices of commercial housing.

Regarding the effect of purchase restriction policy on housing price, Shu and Chen (2017) believed that the "Liberalizing Purchase Order" policy mainly restrains the investment demand of housing, while the impact on 
consumer demand is small. At the same time, the impact of the purchase restriction policy only exists in the short term. Wang and Cui (2017) studied the effect of the purchase restriction policy on the trading volume and housing price in the real estate market and found that the restricted purchase can significantly curb the increase in housing price, but it will show the characteristics of the early stage of price adjustment. Chen and Zhao (2018) used the fixed effect panel model and double difference model to empirically analyze the validity of the limited-credit and limit purchase policies.

However, the researches on the price of commercial housing in Hainan province are a little less. Lin et al. (2011) studied the effect of residential sales area and disposable income of urban residents on the sales price of residential houses in Hainan based on the ridge regression method. Employing the VAR model, Wu (2011) conducted an empirical analysis of the influencing factors of real estate prices in Hainan. In this paper, we first analyzed the price of commercial housing in Haikou from the perspective of supply and demand balance and established a population-demand function to further analyze the impact of the purchase restriction policy on future housing prices.

\section{Methodology}

\subsection{Build the Commercial Housing Price Model}

\subsubsection{Define the Key Factors Based On Grey Correlation Degree}

To start with, we establish the price impact index system from three aspects, that is, supply, demand and macroeconomic environment. As for the factors in supplying, we select four indicators for the completion area of residential housing, the construction area, the sale area and land transaction price. For factors impacting demanding, we select per capital disposable income, CPI and population density. The macroeconomic environment can be divided into the macro-market environment and macro-policy environment. Therefore, we divide macroeconomic environment indicators into GDP, the interest of bank loans, bank line of credit, real-estate investment, and real-estate taxation.

Secondly, we take the housing price as the reference series, and then calculate the correlation degree between the remaining 12 indicators and housing price. By comparing the degree of relevance, the key factor is selected as a variable of the commercial residential price model.

The grey relational analysis method measures the correlation degree based on the degree of similarity or dissimilarity between development factors (Luo \& Liu, 2005). In the process of system development, if the trend of the two factors is consistent, that is, the degree of synchronization changes is relatively high, the correlation degree between these two factors is higher; otherwise, it is lower. The specific calculation steps of the grey relational degree are as follows:

\section{Step 1. Make data dimensionless.}

We first dimensionless the original data using means of averaging.

$$
\begin{gathered}
X_{i}^{\prime}=\frac{X_{i}(k)}{\overline{X_{i}}}(i=1,2, \cdots 13) \\
\overline{X_{i}}=\frac{1}{n} \sum_{k=1}^{n} x_{i}(k), \quad k=1,2, \cdots 15
\end{gathered}
$$

Where, $X_{i}$ reflects the original value of 13 indexes including commodity housing price; $X_{i}^{\prime}$ reflects the standard value after making indexes being dimensionless.

\section{Step 2. Define reference sequence and comparison sequence.}

Taking the sales price of commercial housing as the reference series,

$$
X_{0}^{\prime}=\left\{x_{0}^{\prime}(1), x_{0}^{\prime}(2), \cdots, x_{0}^{\prime}(15)\right\}
$$

And the relevant data of 12 influencing factors are the comparative sequences,

$$
X_{i}^{\prime}=\left\{x_{i}^{\prime}(1), x_{i}^{\prime}(2), \cdots, x_{i}^{\prime}(15)\right\}, i=1,2, \cdots, 12
$$

Step 3. Calculate the difference sequence between each comparison sequence and the reference sequence.

Step 4. Calculate two ranges.

$$
\Delta_{i}(k)=\left|x_{0}^{\prime}(k)-x_{i}^{\prime}(k)\right|, i=1,2, \cdots, 12
$$

$$
\begin{array}{r}
M=\max _{i} \max _{k} \Delta_{i}(k) \\
M=\min _{i} \min _{k} \Delta_{i}(k)
\end{array}
$$


Step 5. Calculate the correlation coefficient between each factor and the price of commercial housing.

$$
\gamma_{0 i}(k)=\frac{m+\xi M}{\Delta_{i}(k)+\xi M}, i=1,2, \cdots, 12
$$

\section{Step 6. Calculate the correlation degree between each factor and the price of commercial housing.}

The correlation degree between comparison sequence and the reference sequence is reflected by multiple correlation coefficients. The correlation information is scattered, and it is not convenient to conduct comparative analysis from the whole. Therefore, we apply the average value of the correlation coefficients in each period of each comparison sequence and reference sequence to quantitatively reflect the correlation degree, it is calculated by,

$$
\gamma_{0 i}=\frac{1}{n} \sum_{k=1}^{n} \gamma_{0 i}(k), i=1,2, \cdots, 12, n=15
$$

\subsubsection{The Establishment of Multiple Linear Regression Model Based on Multivariate Grey Prediction Model}

MGM $(1,1)$, the multi-variable grey forecasting model, is an adaptive grey prediction model that can consider multiple correlation variables. It is a generalization of the $\mathrm{GM}(1,1)$ model under multivariate circumstances, but not a simple combination of GM $(1,1)$ models. And it also differs from the fact that the GM $(1, \mathrm{n})$ model only establishes a single first-order differential equation of $n$ elements, but establishes $n \mathrm{n}$-ray differential equations that are solved by simultaneous solutions to reflect the interaction between variables (Liu, Wang et al.,2007).

The MGM $(1, \mathrm{n})$ model uses a generative sequence to establish specific models. For $\mathrm{n}$ m-dimensional time series data, each sequence represents the dynamic behavior of a factor variable of the system.

$$
x_{i}^{(0)}=\left\{x_{i}^{(0)}(1), x_{i}^{(0)}(2), \cdots, x_{i}^{(0)}(m)\right\}
$$

When having an accumulated generating on $x_{i}^{(0)}$, we can get that,

$$
\begin{gathered}
x_{i}^{(1)}=\left\{x_{i}^{(1)}(1), \quad x_{i}^{(1)}(2), \cdots, x_{i}^{(1)}(m)\right\} \\
i=1,2, \cdots, n \\
x_{i}^{(1)}(k)=\sum_{j=1}^{k} x_{i}^{(0)}(j)
\end{gathered}
$$

Then the first-order ordinary differential equations in the MGM $(1, \mathrm{n})$ model are

$$
\left\{\begin{array}{c}
\frac{d x_{1}^{(1)}}{d t}=a_{11} x_{1}^{(1)}+a_{12} x_{2}^{(1)}+\cdots+a_{1 n} x_{n}^{(1)}+b_{1} \\
\frac{d x_{2}^{(1)}}{d t}=a_{21} x_{1}^{(1)}+a_{22} x_{2}^{(1)}+\cdots+a_{2 n} x_{n}^{(1)}+b_{2} \\
\vdots \\
\frac{d x_{n}^{(1)}}{d t}=a_{n 1} x_{1}^{(1)}+a_{n 2} x_{2}^{(1)}+\cdots+a_{n n} x_{n}^{(1)}+b_{n}
\end{array}\right.
$$

Where, $x_{1}^{(1)}, x_{2}^{(1)}, \cdots, x_{n}^{(1)}$ represents the series for one accumulation; $a_{i j}$ and $b_{i}$ are system parameters.

If we define the following equations,

$$
\begin{gathered}
A=\left[\begin{array}{lll}
a_{11} & & a_{1 n} \\
& \ddots & \\
a_{n 1} & & a_{n n}
\end{array}\right] \\
B=\left[\begin{array}{c}
b_{1} \\
b_{2} \\
\vdots \\
b_{n}
\end{array}\right]
\end{gathered}
$$

Then the equation (12) can be defined by

$$
\frac{d X^{(1)}}{d t}=A X^{(1)}+B
$$

The parameter vector $a_{i}$ in equation (4) can be estimated using the least-squares method, 


$$
\begin{gathered}
a_{i}=\left[\begin{array}{ccccc}
\hat{a_{i 1}} & \hat{a}_{i 1} & \cdots & \hat{a}_{i n} & \hat{b_{i}}
\end{array}\right]^{T}=\left(L^{T} L\right)^{-1} L^{T} Y_{i} \\
i=1,2 \cdot ; n
\end{gathered}
$$

Where,

$$
L=\left[\begin{array}{cccc}
\frac{1}{2}\left(x_{1}^{(1)}(2)+\frac{1}{2} x_{1}^{(1)}(1)\right) & \cdots & \frac{1}{2}\left(x_{n}^{(1)}(2)+\frac{1}{2} x_{n}^{(1)}(1)\right) & 1 \\
\ddots & & \\
\frac{1}{2}\left(x_{1}^{(1)}(m)+\frac{1}{2} x_{1}^{(1)}(m-1)\right) & \cdots & \frac{1}{2}\left(x_{1}^{(1)}(m)+\frac{1}{2} x_{1}^{(1)}(m-1)\right) & 1
\end{array}\right]
$$

Then the time response sequence of the grey $\operatorname{MGM}(1, n)$ model is

$$
\begin{gathered}
X^{(1)}(k)=e^{\hat{A}(k-1)} X^{(1)}(1)+\hat{A}^{-1}\left(e^{\hat{A}(k-1)}-I\right) \stackrel{\cap}{B} \\
k=1,2, \cdots m
\end{gathered}
$$

In the above equation (10), the matrix exponential function $e^{\hat{A} t}$ can be calculated by

$$
e^{\hat{A} t}=I+\hat{A} t+\frac{\hat{A^{2}}}{2 !} t^{2}+\cdots=I+\sum_{k=1}^{\infty} \frac{A^{k}}{k !} t^{k}
$$

By reducing the generation, the original column value is restored to the corresponding variable,

$$
\begin{gathered}
\hat{X}^{(0)}(k)=\stackrel{?}{X^{(1)}}(k)-X^{(1)}(k-1) \\
k=2,3, \cdots m \\
X^{(0)}=X^{(0)}(1)
\end{gathered}
$$

Finally, we can define the multivariate linear regression model based on the grey correlation forecast model is,

$$
P=a_{0}+a_{1} x_{1}^{(0)}(k)+a_{1} x_{2}^{(0)}(k)+\cdots+a_{4} x_{m}^{(0)}(k) \quad m=4
$$

Where, $\mathrm{P}$ is the sales price of commercial housing in Haikou in a month.

\subsection{Develop the Housing Demand Function under Purchase Restriction Policy}

The purchase restriction policy is an administrative measure that reduces the real-estate investment or speculative market demand by restricting the consumption of some people. In other words, the change in the demand for home purchases will be further reflected by the consumer price index (CPI) and the real-estate investment amount, which will in turn affect housing prices. Figure 1 below shows the influence mechanism of restriction policy on housing price (Liu \& Zhang, 2012).

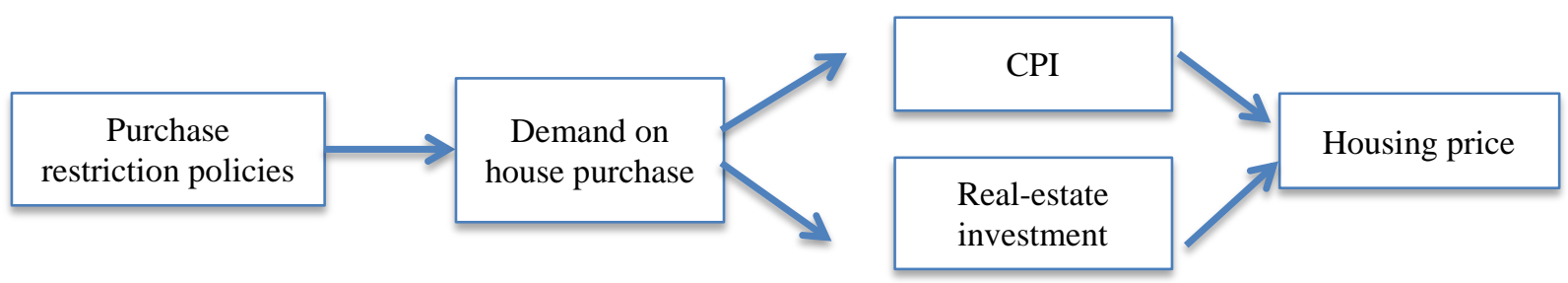

Figure 1. The influence mechanism of restriction policy on housing price

\subsubsection{Define the Population - Purchase Demand Function}

According to the household register location, the population of a city can be divided into household registration population and non-household population. In general, purchase restriction policy is mainly aimed at non-household population, especially those who not live for a certain number of years (usually five years).

The housing purchase demand of the household registration population is mainly affected by their family factors and psychological characteristics. The policy system has almost no influence on them. The purpose of their purchase is mainly to meet the housing demand. The demand for home purchases by household registration population is generally on a logarithmic growth trend. At first, as the population increases, the demand for house 
purchases will increase. However, when the number of registered population in a market reaches saturation, the basic housing needs are met, and the housing purchase demand in this market will show a stable development trend. The figure 2 below shows the demand curve for household registration population in Haikou.

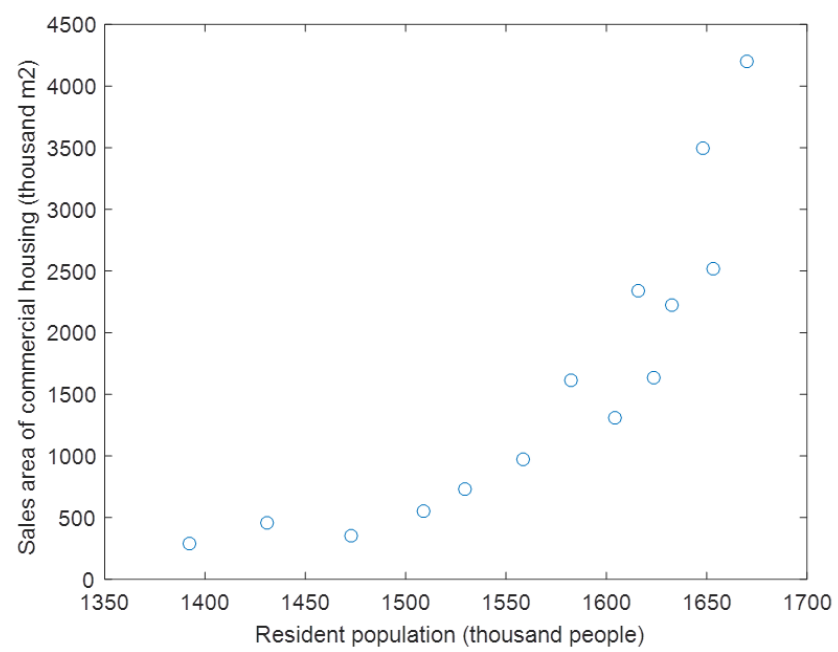

Figure 2. The demand curve of household registration population

In comparison, the housing purchase demand of non-resident is greatly different. According to the restrictions imposed by the purchase restriction policy on the rights of purchase of houses, the non-resident population can be divided into a population that has paid individual income tax (or social security) for a cumulative period of five years and a floating population whose period of residence is less than five years. For those whose living time is less than five years, their purpose of home purchase is mainly to meet the investment demand, which is greatly affected by the policy system. As more and more floating populations flood, the home purchasing demand in this kind of market will also grow rapidly. Therefore, the Population - Purchase demand curve of non-resident is generally on an exponential growth trend, and it is shown in the Figure 3 below.

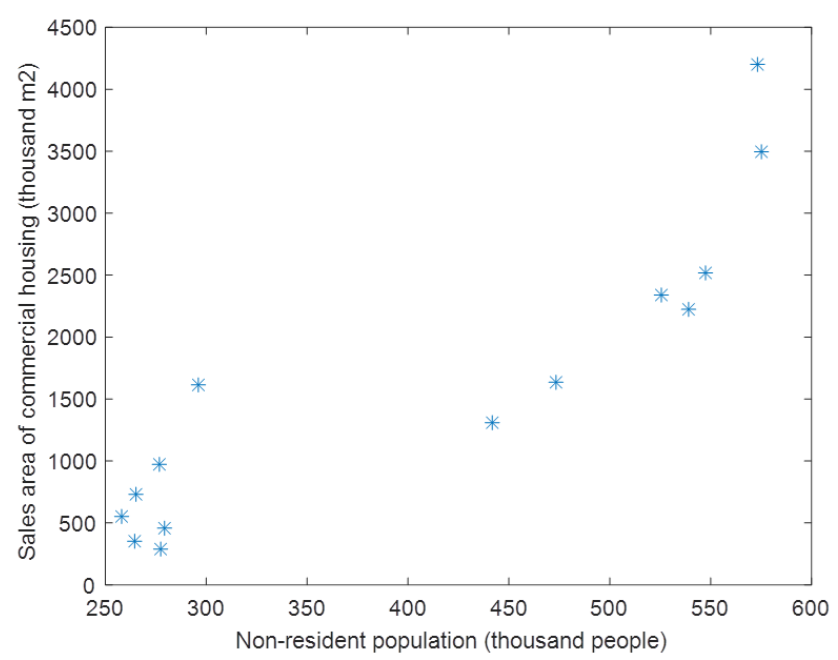

Figure 3. The demand curve of non-resident population

The housing purchase demand is an abstract conception, and here, we employ the sales area of commercial housing to qualify it. Taking the sales area of the commercial housing corresponding to the current period as the dependent variable, we define the demand functions corresponding to the household registration population and the non-household population as follows,

$$
\begin{aligned}
& D_{1}=f_{1}\left(p_{1}\right) \\
& D_{2}=f_{2}\left(p_{2}\right)
\end{aligned}
$$


Where, $p_{1}$ is household registration population, $D_{1}$ is the housing purchase demand of registration population, $p_{2}$ is non-resident population, $D_{2}$ is the housing purchase demand of the non-resident population.

After defining the above two functions, we introduce dynamic weighting factors $\alpha$ and $\beta$, and assign different weights to the two requirements to obtain the demand function of the total population of Haikou as follows,

$$
D=\alpha f_{1}\left(p_{1}\right)+\beta f_{2}\left(p_{2}\right)
$$

Where, $\alpha=\frac{p_{1}}{p_{1}+p_{2}}, \beta=\frac{p_{2}}{p_{1}+p_{2}}$.

\subsubsection{Modify Our Model}

Considering that the sales price of residential houses is a fundamental factor affecting residents' purchase, we add the key factor --house prices to our model. The housing purchase demand is affected by actual house prices and ideal housing prices. In general, the ideal house price based on cost will have an important impact on the demand for the purchase of consumers. At the same time, the purchase behavior of consumers is directly affected by the actual house prices in the current period. As the effective supply of real estate products has a c lag in some extent, there will be some deviation from the ideal price in the current period, and the ideal price of consumers is usually affected by the previous period of housing prices. Therefore, we can conclude that if the ratio of the current housing price to the previous is greater, the demand will reduce accordingly, and vice versa. Based on the above analysis, we define the modified demand function, as shown in following equation (22).

$$
D=\frac{k}{\Delta \text { price }}\left[\alpha f_{1}\left(p_{1}\right)+\beta f_{2}\left(p_{2}\right)\right]
$$

Where, $\Delta$ price is the increment of housing price, and $\Delta$ price $=\frac{\text { price }_{t-1}}{\text { price }_{t-2}} ; k$ is the correction factor for housing price increment, which is the measured parameters.

\subsubsection{The Second Improvement of Our Model}

As there are still some non-household populations who will meet the conditions for accumulated payment of personal tax or social security tax for more than five years in a certain period in the future, and thus they will enjoy the loss of purchase rights due to the purchase restriction policy. For this reason, we introduce $\gamma$, the conversion rate of household registration, to our model. That is,

$$
D=\frac{k}{\Delta \text { price }}\left[(\alpha-\gamma) f_{1}\left(p_{1}\right)+(\beta+\gamma) f_{2}\left(p_{2}\right)\right]
$$

Where, $\gamma=\beta_{t}-\beta_{t-1}$, which represents the number of consumers not affected by restricted purchase policy in the non-household population over a certain period.

We take Haikou (a city in China) as an example. The data in this paper is mainly from the statistical yearbook, prospective database and the CSMAR database of Haikou from 2002 to 2016.

\section{Results and Discussions}

\subsection{Solve the Commercial Housing Price Model}

Calculated by MATLAB software, the grey correlation between various factors and house prices is obtained, as shown in the following Table 1.

Table 1 . The grey correlation between various factors and house prices

\begin{tabular}{cccc}
\hline index & The correlation degree & index & The correlation degree \\
\hline Per capital disposable income & 0.6825 & The completion area of residential housing & 0.7932 \\
CPI & 0.8675 & The construction area of residential housing & 0.8249 \\
The interest of bank loans & 0.6275 & The sales area of residential housing & 0.6977 \\
GDP & 0.4502 & real estate investment & 0.8984 \\
Population density & 0.4912 & Average land exchange price & 0.5623 \\
Bank line of credit & 0.5003 & real-estate tax & 0.4012 \\
\hline
\end{tabular}

From the above table 1, we can see that the correlation between the "real estate investment" series and house prices is the largest, with a value of 0.8984 ; followed by the CPI, the construction area of residential housing and completion area, which are $0.8675,0.8249$, and 0.7932 , respectively.

Therefore, we select CPI, real-estate investment, construction area of residential housing and residential housing 
completion area as independent variables, and employ residential housing sales prices as dependent variables to establish a multiple regression model.

Based on the original data sequences of CPI, real-estate investment, construction area of commercial housing and completion area of commercial housing from March 2016 to December 2017, we calculate the corresponding fitting values of four indexes in Haikou during the corresponding period by multivariate grey prediction model(eqs(1)-(9)). That is, the fitting value sequence of four indexes $\hat{X^{(0)}}(k)=\left(\hat{x_{1}^{(0)}}(k), \hat{x_{2}^{(0)}}(k), \hat{x_{3}^{(0)}}(k), \hat{x_{4}^{(0)}}(k)\right)^{T}$ is shown in following table 2 .

Table 2. The gray forecast processing result of each index in Haikou

\begin{tabular}{ccccc}
\hline month & $\begin{array}{c}\text { The real-estate investment } \\
\text { (million yuan) }\end{array}$ & $\begin{array}{c}\text { Construction area } \\
\text { (million square meters) }\end{array}$ & $\begin{array}{c}\text { Completion area } \\
\text { (million square meters) }\end{array}$ & CPI \\
\hline December 2017 & 8750.58 & 2022.91 & 350.65 & 103.64 \\
November 2017 & 8284.24 & 2005.67 & 328.47 & 104.48 \\
October 2017 & 7829.44 & 1988.82 & 308.32 & 105.19 \\
$\ldots \ldots$ & $\ldots \ldots$ & $\ldots \ldots$. & $\ldots \ldots$ & $\ldots \ldots$ \\
November 2015 & 2478.56 & 1643.15 & 116.91 & 102.50 \\
\hline
\end{tabular}

Calculated by MATLAB, we can get the estimated values of parameters. The following table 3 and table 4 shows the regression results.

Table 3. Summary of the regression process

\begin{tabular}{|c|c|c|c|c|}
\hline Model & $\mathrm{R}$ & Square $R$ & Adjusted square $R$ & estimated standard error \\
\hline 1 & 0.994 & 0.988 & 0.985 & 215.900 \\
\hline
\end{tabular}

Analyzing the above table 3, we can find that the multiple correlation coefficient of the regression equation is 0.994 , the multiple coefficients of determination is 0.988 , and adjusted multiple coefficients is 0.985 . The estimated standard error of regression equation is 215.900 , which indicates that the fitting goodness of this equation is higher.

The variance analysis of the regression equation significant $\mathrm{F}$ test is shown in Table 4 below.

Table 4. The variance analysis

\begin{tabular}{cccccc}
\hline The variance source of explained variable & sum of squares of deviations & degree of freedom & mean square & F statistics & prob \\
\hline Regression sum of squares & 66662105.429 & 4 & 16665526.357 & 357.233 & 0.000 \\
residual sum of squares & 793077.890 & 17 & 46651.641 & & \\
total dispersion square sum & 6745583.318 & 21 & & & \\
\hline
\end{tabular}

The above Table 4 shows that for the housing sales price, the total dispersion square sum is 6745583.318 , the regression square sums and mean squares are 66662105.429 and 16665526.357 respectively, the residual square sums and mean squares are 793077.890 and 46651.641 respectively, and the F-test statistics are observed. The value is 357.233 and the corresponding probability $\mathrm{P}$ is 0.000 . The results demonstrate that the final regression equation should include four variables of CPI, real estate investment, residential housing construction area and completion area, and the equation fitting effect is better.

To sum up, the estimated value of the available parameter sequence is

$$
\hat{a_{0}}=-23238.127 \quad \hat{a}=(0.114,-21.298,55.918,573.681)
$$

Therefore, the multiple linear regression model of commercial housing is

$$
\hat{P}(k)=-23238.127+0.114 \hat{x_{1}}(k)-21.198 \hat{x_{2}}(k)+55.918 \hat{x_{3}}(k)+573.681 \hat{x_{4}}(k)
$$

Where, $\hat{P}(k)$ represents the sales price of commercial housing, and $\hat{x_{1}}(k), \hat{x_{2}}(k), \hat{x_{3}}(k), \hat{x_{4}}(k)$ represent real-estate investment, construction area of commercial housing, completion area of commercial housing and CPI respectively.

Through the testing of equation significance, we get that $R^{2}=0.954$, and $F=326.5>3.2$, which indicates that our 
model is significant. In other words, the response variable $\hat{P}$ has a close relationship with $\hat{x}(k)$.

\subsection{Solve the Purchase Demand Function}

After several simulations, we obtain two kinds of demand functions as follows equation (25) and (26)

$$
\begin{gathered}
D_{1}=f_{1}\left(p_{1}\right)=e^{17.508-1982.825 / p_{1}} \\
D_{2}=f_{2}\left(p_{2}\right)=26.891 p_{2}+0.431 p_{2}^{2}+469.502
\end{gathered}
$$

Performing a significant test on equation (21), we find that $R^{2}=0.942$, and the $\mathrm{F}$ value is $227.258>3.2$, which demonstrate that both models are significant and have a good fitting effect

Based on the relevant data of Haikou from 2002 to 2016, we employ SPSS software to obtain the functional relationship between CPI and housing purchase demand, real estate development investment and housing purchase demand respectively through several simulations, as shown in following equation (27) and (28),

$$
\begin{gathered}
C P I=-0.219 D+0.002 D^{2}-2.083 \times 10^{-6} D^{3}+107.985 \\
\text { investment }=-156.169 D+0.949 D^{2}-0.001 D^{3}+9597.155
\end{gathered}
$$

Where, $C P I$ is consumer price index, investment is real-estate investment, and $D$ is housing purchase demand ,that is, the sales area of commercial house. Performing significant tests on equation (25) and (26) respectively, we get that $R^{2}$ is 0.863 and 0.977 respectively, the F value is 117.628 and 216.027 respectively, which shows that these two models are significant, that is, the response variable CPI and investment has a close relationship with the regression variable $D$.

Calculated by MATLAB, we get the purchase demand function model coefficient $k$ is 0.92 .

\subsection{The Housing Price Forecast under Restriction Policy}

We first use the grey prediction model to predict the number of registered and non-resident populations in Haikou from June 2018 to May 2019. Then the result obtained is substituted into the demand function model (Equation 25 and 26) above to obtain the sales area of commercial housing under the influence of the purchase restriction policy within the next year. After that, calculated by above equation 25 and 26, we get the monthly CPI and real estate development investment amount in the next year. Moreover, applying the grey prediction method, we get the completion and construction area of residential houses in the year to come. Finally, combining with the above multiple linear regression model (equation 24), the sales price of commercial housing in Haikou within the next year after the introduction of the purchase restriction policy is observed.

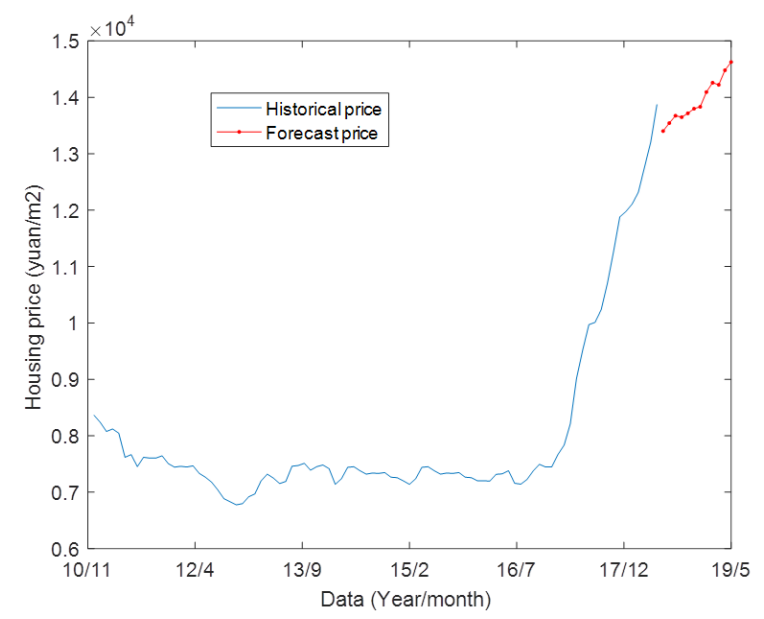

Figure 4 . The housing price change trend in haikou under restricted policy

In the above figure 4, the blue line reflects the fluctuations in housing price of Haikou from November 2010 to April 2018. The red line represents the predicted fluctuations in housing price from June 2018 to May 2019 in 2018. Observing Figure 9, we can see that after the initial implementation of the purchase restriction policy, the housing price in Haikou will show a downward trend, but it soon began to rebound, basically returning to the original price within six months. To a certain extent, this is because the restriction policy restricts the purchase of commercial housing by a large number of non-resident populations. As a result, market demand has been greatly 
reduced, and house prices have declined accordingly. However, as the price drop will inevitably bring an increase in market demand, the registered resident may have an irrational investment in buying a house, leading to increasing in house prices. In conclusion, the purchase restriction policy has a short-term effect, but if it is implemented in the long term, it will break the balance between supply and demand in the housing market and may have a negative impact on the real estate market.

\section{Conclusions}

With the fast development of the social economy, housing prices in China have been rising rapidly. The real estate issue has increasingly attracted the attention of the community. As the "barometer" of the real-estate industry, the real-estate prices have become an important indicator of the government's macro-control. According to the historical fluctuations of commercial housing prices in Haikou, we predict the trend of future house prices combining with the purchase restriction policy. Firstly, we use the grey relational model to extract the main factors affecting housing prices. Secondly, we establish a modified multiple linear regression model based on GM $(1, n)$ to calculate the price of residential housing. Finally, introducing the population-purchase demand function, we predict the housing prices in the coming years under purchase restriction policy. And we conclude that purchase restriction policy cannot solve the problem of skyrocketing housing prices in Haikou at its source.

We innovatively propose the purchase demand model under the restriction policy. First of all, we find that the demand between household registration and the non-household population is different, so we establish two corresponding demand functions respectively. Then we define the proportion of these two types of population as a dynamic weighting factor to dynamically weight two demand functions. Moreover, considering that the impact of housing prices on demand is decisive and the lag effect of house price changes, we creatively put forward the concept of house price increase ratio as a modifying factor to promote our model. In the end, because non-household population will transform into registration population within a certain period, we introduce the transform factor to secondly improve our model, which make the model more reasonable. In a word, the population-purchase demand function model constructed in this paper fully considers various practical factors, and it has practical reference significance and promotion value for the study of the impact of macro-policy control on real estate prices.

\section{References}

Dang, L., \& Sifeng, L. (2005). Research on Grey Association Decision Method. Chinese Journal of Management Science, 13(1), 101-106. http://doi.org/10.3321/j.issn:1003-207X.2005.01.018

Donghong, W., Wei, W., Biao, L., Chaoyang, W., \& Yuqin, X. (2018). Research on Spatial Differentiation Characteristics and Mechanism of Commercial House Prices in Wuhan: Based on Geostatistical Analysis. Journal of Shandong Normal University (Natural Science), 1. http://doi.org/10.3969/j.issn.1001-4748.2018.01.016

Hualei, Y., \& Lingyun, H. (2016). Population Migration, Urbanization and the Housing Market. China Soft Science, 12, 91-104.http://doi.org/10.3969/j.issn.1002-9753.2016.12.010

Huan'e, W., \& Ming, C. (2017) .The impact of real estate purchase restrictions on real estate market turnover and house prices - Take S as an example. Commercial Times, 24, 178-180. http://doi.org/10.3969/j.issn.1002-5863.2017.24.056

Malpezzi, S., Ozanne, L., \& Thibodeau, T. G. (1987). Microeconomic estimates of housing depreciation. Land Economics, 63(4), 372-385. http://doi.org/10.2307/3146294

Wei, S., Xuefei, S., \& Wei, C. (2017). Research on the Influencing Factors of Real Estate Prices in Tianjin: Based on the Improved Entropy-Grey Relation Model. Price Monthly, 12, 1-5. http://doi.org/10.14076/j.issn.1006-2025.2017.12.01

Wendian, L., Fengxiao, W., \& Yourun, L. (2007). Multivariate Linear Regression Model Based on Multivariate Grey Prediction Model. Science Technology and Engineering, 7(24), 6403-6406. http://doi.org/10.3969/j.issn.1671-1815.2007.24.030

Xiao, L., Jingyu, Z., \& Xiaohua, H. (2011). Research on the Influencing Factors of Housing Sales Price in Hainan Province Based on Ridge Regression. Journal of Hainan Normal University (Natural Science Edition), 24(3), 257-259. http://doi.org/10.3969/j.issn.1674-4942.2011.03.007

Xu, C., \& Xinquan, Z. (2018). An empirical study on the effect of purchase limit loan policy on house price. Wuhan Finance, 1, 21-26. http://doi.org/10.3969/j.issn.1009-3540.2018.01.007

Xuepin, W., \& Mingheng, L. (2011). Empirical research on the influencing factors of Hainan real estate prices: 
An analysis based on the var model. Hainan Finance, 12, 21-24. http://doi.org/10.3969/j.issn.1003-9031.2011.12.06

Yang, S., \& Ling, C. (2017). The influence of the "restriction order" under the dual attribute of housing on the housing market. The World of Survey and Research, 12, 8-15. http://doi.org/10.13778/j.cnki.11-3705/c.2017.12.002

Yu, H. (2010). Dynamic analysis of the influence of land prices and residents' income on commercial housing prices: an empirical study based on the state space model. Economics and Management Research, 10, 24-28. http://doi.org/10.3969/j.issn.1000-7636.2010.10.004

Zhou, \& Nan. (2015). Empirical research upon the influence of interest rate changes upon the real estate market price. Academic Circles, 6. http://doi.org/10.3969/j.issn.1002-1698.2015.06.037

\section{Copyrights}

Copyright for this article is retained by the author(s), with first publication rights granted to the journal.

This is an open-access article distributed under the terms and conditions of the Creative Commons Attribution license (http://creativecommons.org/licenses/by/4.0/). 